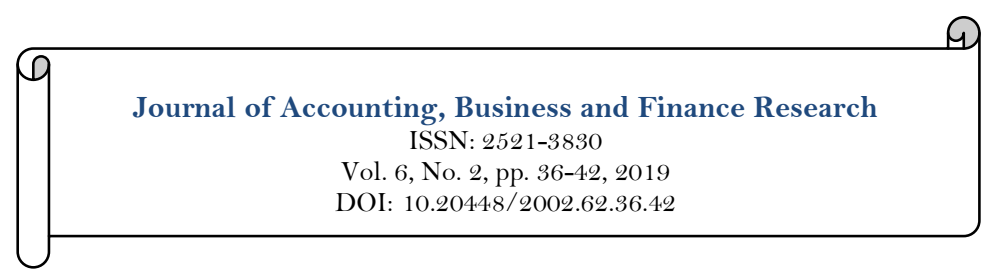

\title{
Research on the Characteristics of Uncertainty of China's Economic Policy
}

\author{
Ting Liu ${ }^{1 *}$ \\ Rongxia $\mathbf{L v}^{2}$ \\ ${ }^{1,2}$ PhD Student, Central University of Finance and Economics, China. \\ ${ }^{2}$ Email:liutingcyl@163.com
}

\section{Abstract}

As a socialist country, China has made great progress in its economy since the implementation of the reform and opening-up policy in 1978. Economic policy plays an important role in economic development. But with the arrival of the new normal economy, slow development has become the main problem facing us now, even the downward pressure of the economy. Therefore, the Chinese government constantly adjusts its economic policies to adapt to the development of the economy. Appropriate changes in economic policies are conducive to better play the role of adjustment, but frequent changes in policies will hinder the development of the economy to a certain extent. This paper analyses the characteristics of China's EPU index tries to find the characteristics of the index and puts forward some policy recommendations. By using the GARCH model to analyze China's EPU index, we find that the index has the following characteristics: volatility clustering, autocorrelation and heteroscedasticity. And through the trend chart of the index, we can see that in recent years, China's EPU index has been improving in general.
Keywords:

China EPU index

GARCH model

Characteristic analysis.

JEL Classification:

A19.

Licensed:

This work is licensed under a

Creative Commons Attribution 4.0

License.

Publisher:

Scientific Publishing Institute

Accepted: 29 April 2019

Published: 16 May 2019

Funding: This study received no specific financial support.

Competing Interests: The authors declare that they have no competing interests.

\section{Introduction}

Ten years ago, the global financial crisis had a far-reaching impact on the economic development and national life of various countries, and the downturn in development became the norm of major economies. In response to the heavy losses caused by the large-scale economic crisis, various countries have introduced different rescue measures, and hope to save their own economic situation. The implementation of different rescue measures means that different economic policies have been formulated at the national level to play the role of regulators. Especially in some countries which used to pursue complete market freedom, even before they would not interfere in the operation of the economy, but in the face of the crisis, these countries had to change their previous strategies and begin to implement economic policies to intervene in and regulate the development of the economy. However, in the face of the crisis, those countries that initiated policies to regulate the economy before the crisis also began to change the old policies and implement new ones to adjust the economy. Economic policy in each economy, from less to more, has entered a changeable state, which is the origin of the uncertainty of economic policy in recent years. For example, after the 2008 economic crisis, the United States changed its previous interest rate policy and implemented ultra-low interest rates in the hope of increasing market liquidity and thus reducing the large-scale recession caused by the crisis. Japan has implemented a series of stable economic policies to save its economic situation. China quickly launched a four trillion plan to change its trade policy, thus stabilizing the economic discovery and improving the situation. However, the emergence of economic crisis is not the only reason for the change of economic policy. War, 
natural disasters and internal malfunction may lead to frequent changes of economic policy, leading to uncertainty of economic policy.

Since 1978, China began to implement the policy of reform and opening up. After more than 40 years of development, China's economy has made a rapid leap, and people's living standards have improved significantly. A series of great achievements have been made. The planned economy has been successfully transformed into a socialist market economy. Although the government's intervention in the economy is gradually decreasing, the government still plays an important role in regulating the direction of economic development. Compared with some big countries in Europe and America, the economic policies pursued by the Chinese government still play an important role. Therefore, in order to better maintain the high-speed operation of the economy, the Chinese government constantly adjusts its economic policies to adapt to the development of the market economy. The operation of the economy will not only be affected by the economic policy itself, but also by the frequent changes of the economic policy, which will have an important impact on the economy. Originally, based on the changes of China's economic policies in recent decades, this paper studies the characteristics of the changes in economic policies and their impacts on the development of the country in all aspects. Studying the changes of economic policies plays an important role in stabilizing economic development and maintaining national stability and security.

\section{Literature Review}

At the Nineteenth People's Congress held in China in 2018, it was pointed out that the global economy, politics and culture are undergoing far-reaching changes. Various uncertainties and instability are prominent, and the growth of the world economy lacks basic impetus. Therefore, in the face of these uncertainties, it is necessary to adjust policies in time to adapt to the development of the situation. As for the uncertainty of economic policy, scholars have been keeping pace with the times, mainly divided into three forms. Different forms of division are mainly based on the different definitions and quantifications of economic policy uncertainty.

In the study of economics, we must quantify the objects we want to study and convert them into data indicators so as to make a scientific, comprehensive and rational analysis of economic factors. Therefore, the quantification of economic policy uncertainty has become the focus and difficulty of research. The first is to use leadership turnover as a quantitative indicator of economic policy uncertainty. Different leaders have different preferences, which include bad preferences for risk, different criteria for judging economic forms, and even different aesthetics. Different preferences are bound to lead new leaders to make different decisions than previous leaders. For example, in the United States and some European countries, the change of leadership caused by each election can represent the uncertainty of economic policy. The more leaders change, the greater the index representing uncertainty in economic policy. Hong and Kostovetsky (2010) argues that leaders of different parties differ greatly in policy. The existence of such differences often becomes a powerful magic weapon for them to defeat rival parties and become "winners" (Hong \& Kostovetsky, 2010). Especially when people are dissatisfied with the previous leadership, the existence of such differences will inevitably lead to policy uncertainty. Even if the leaders of the same party win the election, because of the different electoral backgrounds, the original policy will change. Compared with other countries such as Europe, China's leadership turnover is mainly due to the tenure system of leaders and the system of exchange between different places. Xu, Qian, and $\mathrm{Li}$ (2013) used the replacement of the Secretary of the CPC Municipal Committee as a measure of policy uncertainty, it concluded that private investment capital would be significantly affected by policy uncertainty (Xu et al., 2013). In his opinion, before and after the increase of uncertainty, i.e. the replacement of officials, investment expenditure would decrease significantly. Guo, Wang, and $\mathrm{Li} \mathrm{(2016)}$ followed Xu Yekun's measurement index of policy uncertainty and drew the conclusion that R\&D investment will decrease when uncertainty increases (Guo et al., 2016).

The second way of dividing economic policy uncertainty is to quantify indicators based on the occurrence of major events. For example, in the financial crisis mentioned in the previous article, when the time of significant impact occurs, the management will immediately respond to the stress and quickly adjust the original policy to adapt to the current situation. In addition to the financial crisis, major events such as natural disasters, terrorist attacks, wars and turmoil may represent major changes in economic policy. Chau and Wang (2014) studied the impact of civil strife in the Arab world on stock market volatility using the Arab Spring as a measure of policy uncertainty (Chau \& Wang, 2014). Huang, Wu, and Yu (2015) uses international political crisis events as proxy variables of policy uncertainty to test its impact on corporate dividend policy Huang et al. (2015).

The third quantitative indicator of economic policy uncertainty is the economic policy uncertainty index. Baker, Bloom, and Davis (2016) of Stanford University and the University of Chicago creatively proposed the Economic Policy Uncertainty Index (EPU Index) to measure the uncertainty of economic policies in major global economies (Baker et al., 2016). Scott and Bloom (2013) defined the uncertainty of economic policy as the economic risk caused by the uncertainty of government's future policy (Scott \& Bloom, 2013). Its research team has constructed economic uncertainty indices for 12 large economies, including the United States, Europe, Japan, Russia, China and other economies, but in the process of conducting economic policy 
uncertainty indices for each economy, Baker and others have adopted different channels of combing. Taking the uncertainty index of American economic policy as an example, Baker et al. (2016)) adjusted and standardized the news index, the invalidation index of tax laws and regulations, and the difference index of economic forecast, so as to get the quantitative index of the uncertainty index of American economic policy. For China's economic policy uncertainty index, Baker et al. (2016) are the subjects of analysis for the South China Morning Post, Hong Kong's largest English newspaper, by searching for economic keywords such as "economy", "uncertainty", "legislation", "rule system", "deficit". After normalizing the standard mean and standard deviation, and giving weight according to the corresponding probability, the EPU index of China is constructed by data synthesis method. Compared with the two methods mentioned above, the current popular EPU index has greater advantages, more scientific and advanced. At the same time, it has become an index widely used by a large number of scholars in the field of uncertain economic policy research. This paper takes the EPU index of China formulated by Baker et al. (2016) as the main research object to analyze the characteristics and impact of China's EPU index.

\section{Characteristic Analysis of EPU Index in China}

\subsection{Descriptive Analysis}

Descriptive analysis of economic policy uncertainty, including monetary policy, fiscal policy and trade policy and other policy factors changes, based on different historical backgrounds and influencing factors, economic policy changes are sometimes very frequent, sometimes slow. Since China implemented the policy of reform and opening up the domestic economy has maintained a high growth rate. However, in recent years, due to the role of international environment and economic operation law, China's economy has entered a new state, that is, the slow growth stage, known as the new normal. Whether the rapid development in the early stage or the steady development now, we need to constantly adjust economic policies to adapt to the changes in the environment, so that economic policies can better promote economic development, maintain economic stability and stability of people's lives. This paper takes the EPU index of China formulated by Baker et al. (2016) as the main research object. First of all, we should make a simple descriptive analysis of the EPU index of China. At the same time, in order to better study the characteristics of China's EPU index, the article also makes a simple comparison and analysis of the EPU index of other world economies closely related to China's economy. The following chart shows the EPU indices of China, Europe and some countries in America.

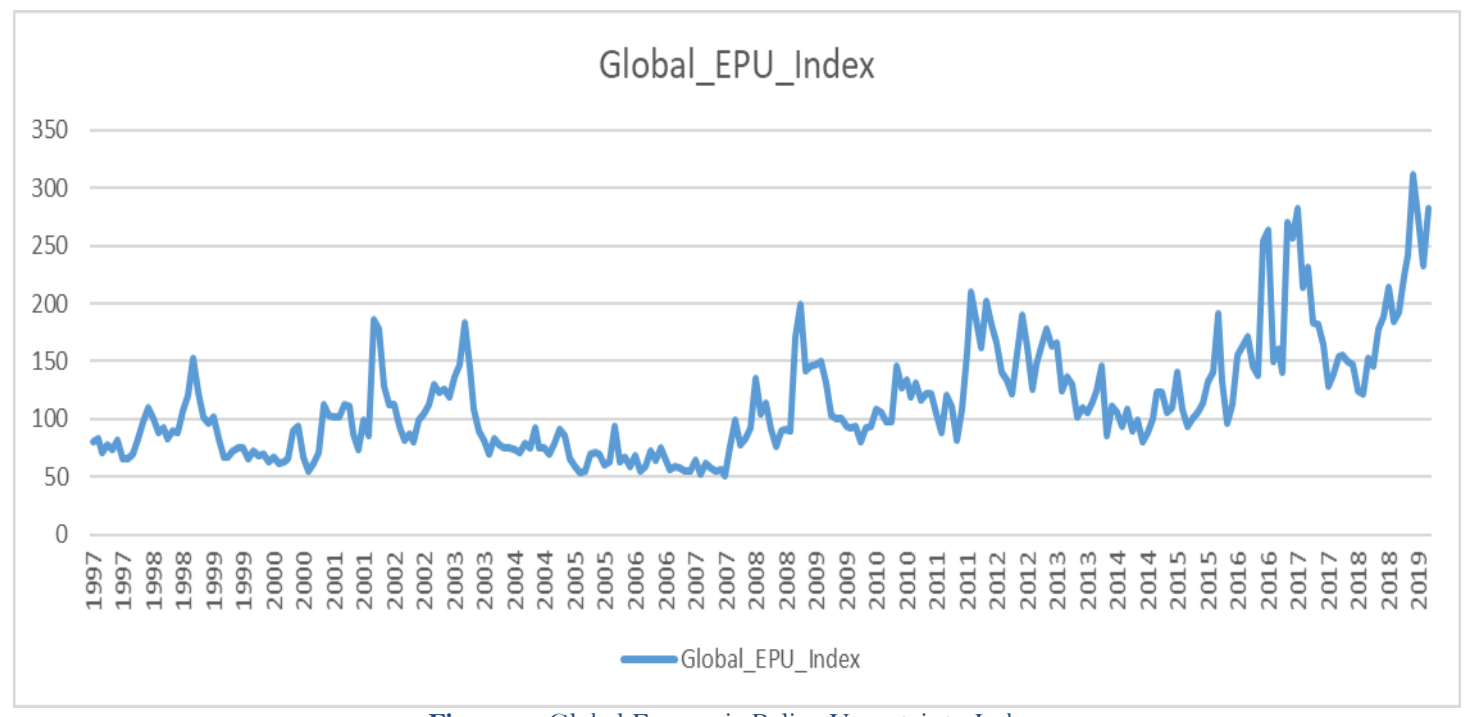

Source: http: / /www. policyuncertainty. com/.

Figure 1 shows the global EPU index which is the monthly data from January 1997 to March 2019. It is calculated based on the comprehensive weighting of economic policy uncertainty of each economy in the world. Because it is affected by too many factors, the characteristics of the index are not very obvious. However, according to the analysis, we can see that in the beginning of the new century in 2000 and 2008 , there are obvious signs of increase, while in 2016 and 2017 to reach new heights. 


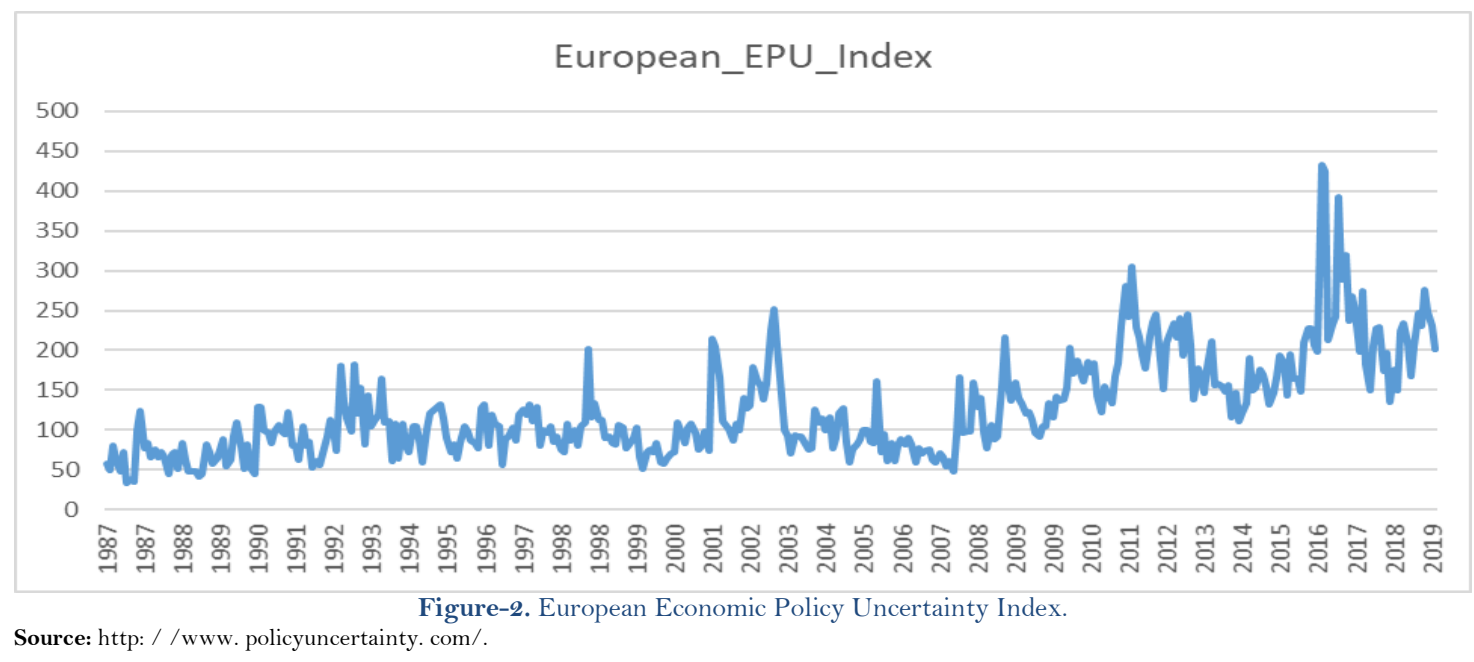

As shown in Figure 2 Baker formulated the EPU index of Europe, which includes the EPU index of many countries, such as Germany, Britain and France. The reason why they chose the comprehensive EPU index of Europe is that, as a developed region, the economic situation of Europe will profoundly affect the global economic development and also have an important impact on China's economy. Second, the comprehensive index of Europe, especially the existence of the European Union, makes the index more representative. According to the chart above, the data in 2000 and 2008 have increased significantly, and reached a new high in the end of 2016 and 2017. Unlike the previous global EPU index, in 2019, the European EPU index is relatively low and does not show an increasing trend. The reason may be that the current situation in the EU is relatively stable, and the previous plan of Britain's de-EU has not been implemented, showing a peaceful situation.

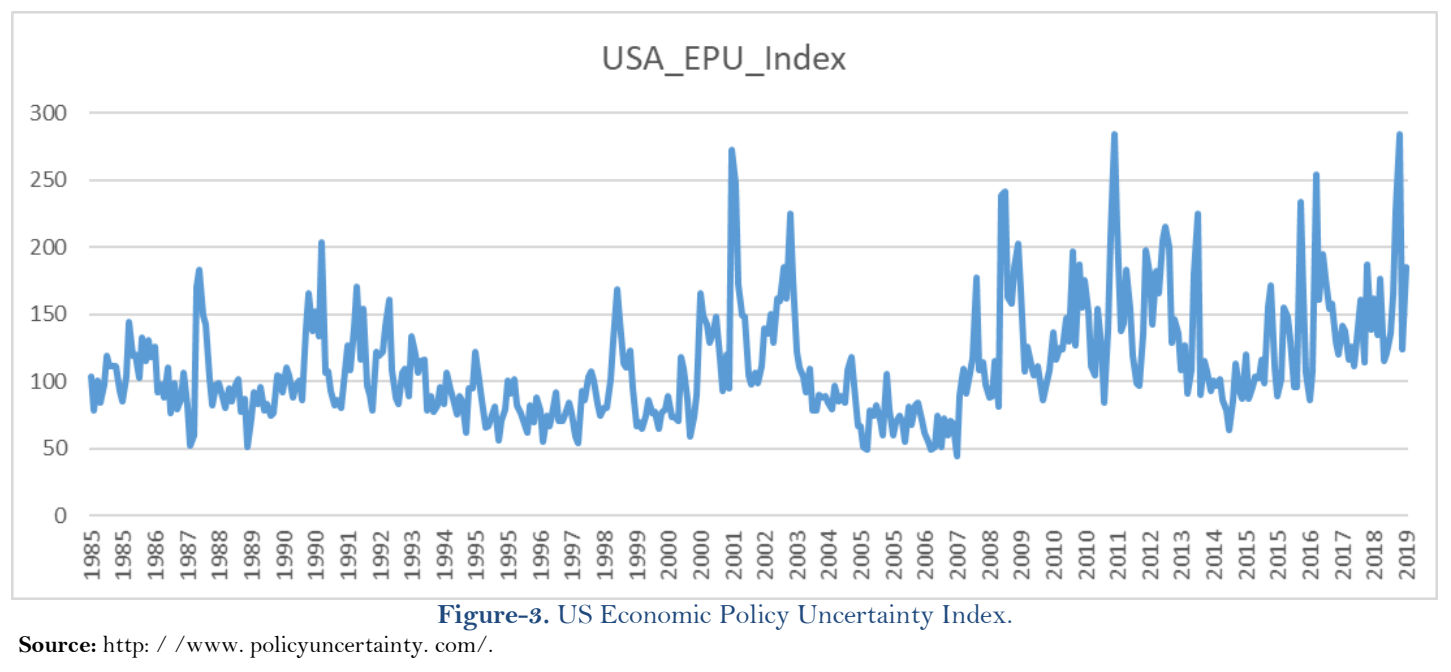

As a superpower in the world, the uncertainty of economic policy of the United States not only affects its own economic situation, but also affects the whole world. More importantly, the United States is a bipartisan country. Every presidential election is a huge dispute. Different political parties often take different measures on major economic policies. These factors also make the fluctuation of the EPU index in the United States more intense. As shown in Figure 3. In 2000, 2008 and 2016, without exception, the U.S. EPU index has increased significantly. At the same time, it is worth noting that the U.S. withdrawal from Iraq in 2011, while economic policy has improved considerably. Perhaps for better economic development, Congress has shifted more attention to the economy. After the new President Trump came to power, the EPU index reached a new historical peak as soon as the economic policy of the United States fluctuated obviously. It is believed that under the leadership of this administration, the EPU index of the United States will continue to maintain a larger growth trend. 


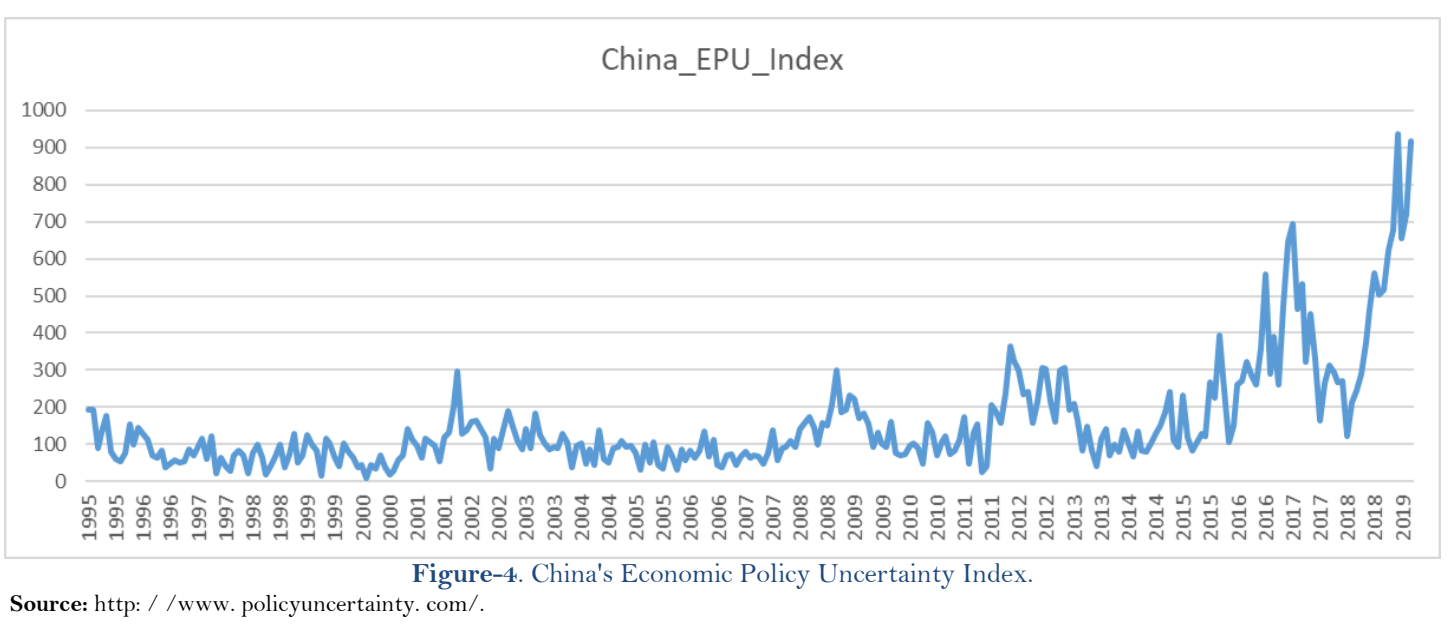

Last but not least, as can be seen from Figure 4: China's EPU index, which is from January 1995 to March 2019. Overall, compared with Europe and the United States, China's EPU index did not fluctuate significantly before 2016. Although it increased in 2000 and 2008, it did not fluctuate very much. But it is undeniable that, although compared with its own data, the fluctuation is not large. But since 2016, China's EPU index has suddenly risen, even tripling its previous peak. Before 2016, the maximum value of China's EPU index was less than 400, but at the end of 2018, it was more than 900. This change is significant and historic. We have to consider the reasons behind the sudden explosion of the EPU index. China has been carrying out the policy of reform and opening up for more than 40 years. In these years, China's economy has achieved a rapid leap and become a superpower in the world. However, with the development of the law of economic operation, since 2015, China's economic development has slowed down gradually, even showing signs of economic downturn. In order to adapt to the new normal economic operation, the state and the government have to adjust their economic policies rapidly, and constantly adopt new monetary, fiscal and trade policies in order to cope with the downward pressure of the economy and maintain the rational and effective operation of the economy.

\subsection{GARCH Model}

This paper uses GARCH model to analyze the important characteristics of EPU index in China. EPU index is a set of time series. When studying time series, we should first consider its autocorrelation and heteroscedasticity. ARCH model is also called autocorrelation conditional heteroscedasticity model. GARCH model is a further extension of ARCH model, which is called generalized autoregressive conditional heteroscedasticity model. So the autocorrelation analysis of time series can be simply summed up as follows :

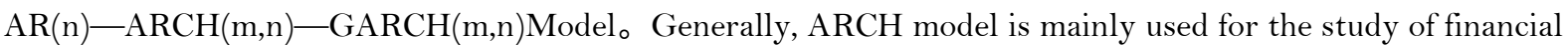
time series. This paper attempts to apply this model to the study of the characteristics of China's EPU index, which is an innovation. Next, we need to introduce GARCH model, which is divided into mean equation and variance equation.

(1) Mean value equation :

$$
y_{t}=C+\sum_{i=1}^{R} \phi_{i} y_{t-1}+\varepsilon_{t}+\sum_{j=1}^{M} \theta_{j} \varepsilon_{t-j}+\sum_{k=1}^{N x} \beta_{k} \mathrm{X}(t, k)
$$

(2) Variance equation:

$$
\sigma_{t}^{2}=k+\sum_{i=1}^{p} \mathrm{H}_{i} \sigma_{t-i}^{2}+\sum_{J=1}^{Q} \mathrm{~A}_{j} \varepsilon_{t-j}^{2}
$$

(3) Coefficient condition :

$$
\sum_{i=1}^{P} G_{i}+\sum_{j=1}^{Q} \mathrm{~A}_{j}<1
$$

In the above equation, $\mathrm{C}$ is a conditional mean constant and $\Phi$ is an autoregressive coefficient. $\theta$ is moving average coefficient (MA), Bis the coefficient of explanatory variable。K is the conditional variance constant - $\mathrm{P}$ and $\mathrm{Q}$ represent the order of the model, respectively. Gi is the coefficient of GARCH model. Equation 1 is the mean value equation, Through Equation 1, we can see that the dependent variable YT is affected not only by its lag term, but also by the lag term of mean and mean. Equation 2 is a variance equation. From the format of Equation 2, we can see that variance is not only autocorrelation, but also related to mean. These are the components of GARCH model. Through the calculation of these two models, the EPU index of China has autocorrelation. Equation 3 is the basic condition for this type of model. 
3.3 Empirical Results

In this paper, the EPU index of China is processed by MATLAB software, and the following results are obtained:

Table-1. Running results of GARCH model of EPU index in China

\begin{tabular}{c|c|c|c}
\hline Parameter & Value & Standard Error & T Statistic \\
\hline Constant & 0.103218 & 0.0421791 & 2.44712 \\
\hline GARCH $\{1\}$ & 0.44367 & 0.158405 & 2.80086 \\
\hline ARCH $\{1\}$ & 0.257353 & 0.0906887 & 2.83777 \\
\hline Offset & -0.00826884 & 0.0329917 & -0.250634 \\
\hline \multicolumn{2}{l}{ Source: http: / /www. policyuncertainty.com/. }
\end{tabular}

Source: http: / /www, policyuncertaintycom/.

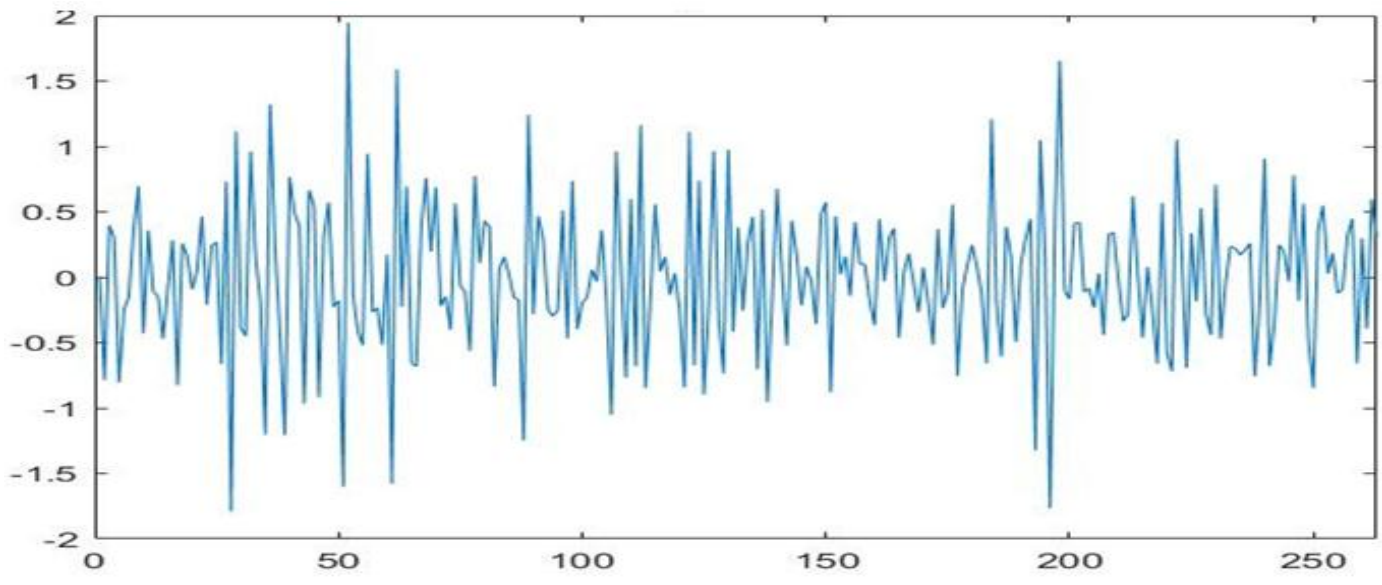

Figure-5. Volatility Aggregation of China's EPU Index.

Source: http: / /www. policyuncertainty. com/.
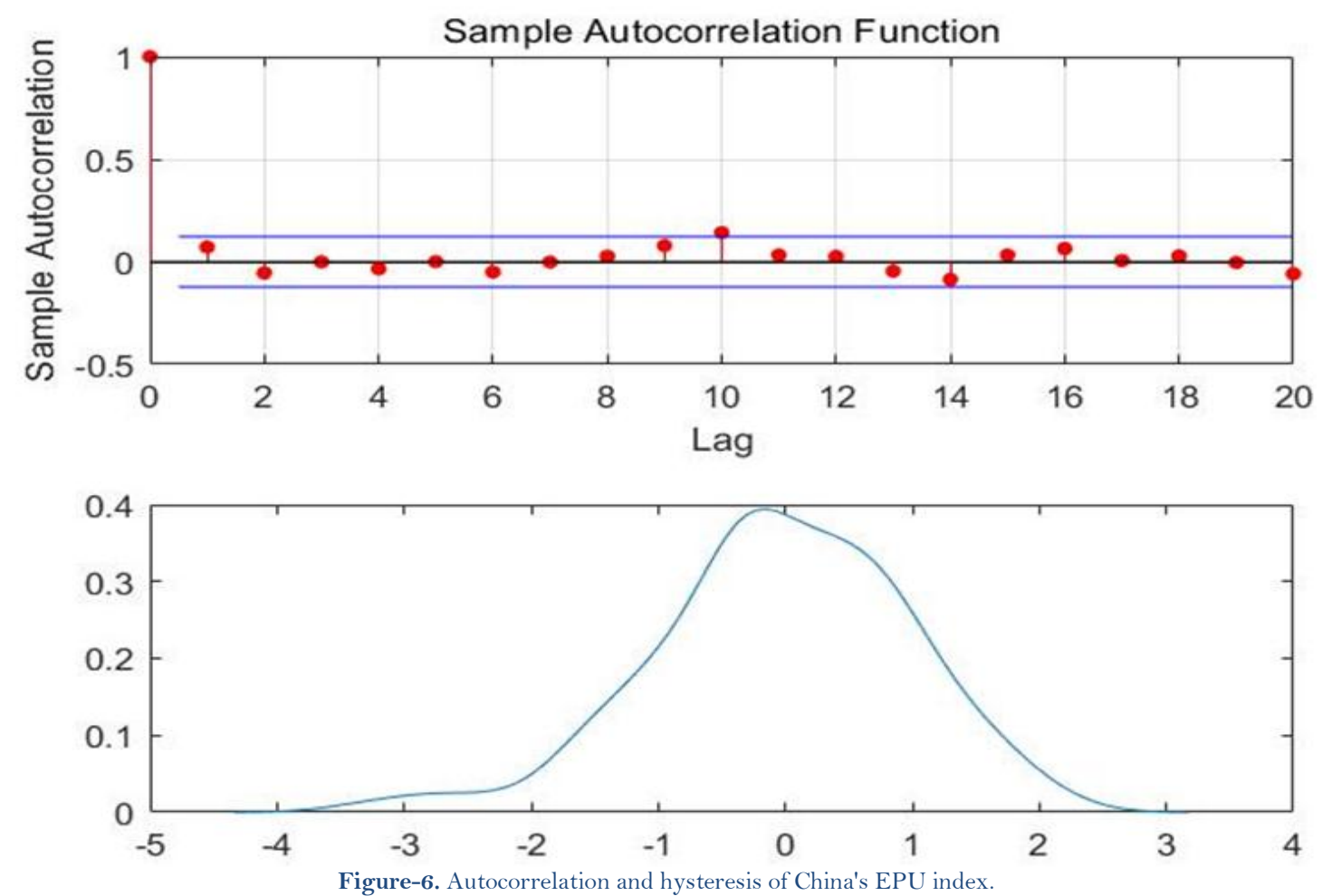

Source: http: / /www. policyuncertainty. com/.

Let's analyze Figures 5 and 6 from the above data, we can see that the uncertainty of China's economic policy has three characteristics: the first is data aggregation, that is, when China's EPU index has a big fluctuation, there will be a big fluctuation in the next period, but the fluctuation in the current period is very small, and the fluctuation in the later period is relatively large, which means that the violent fluctuation often does not occur alone, but rather. Occurs in succession in the adjacent time. The second characteristic is selfcorrelation. From the above experimental results, we can see that the coefficient of GARCH $\{1\}$ is 0.44367 , 
that is, the current EPU index has a greater relationship with the previous EPU index. This conclusion can also be seen from the chart. The third characteristic is heteroscedasticity. The variance of the fluctuation of EPU index does not conform to the orthodox distribution, but is heteroscedasticity. This shows that the EPU index of each period is affected by different factors and can't be predicted completely.

By analyzing the above characteristics of China's EPU index, we need to think about the reasons behind these characteristics. In the previous article, we mentioned that the uncertainty of economic policy is caused by many factors, that is, the occurrence of major events, the change of leaders, natural disasters, wars and other factors may lead to changes in economic policy. When a certain kind of abnormal events occur, it is not onetime for the management to make some policy adjustments. It is necessary to constantly adjust policies to combat the emergence of abnormal events. The constant adjustment of policy means the agglomeration and autocorrelation of fluctuations.

\section{Conclusion}

Firstly, in the literature review, this paper lists three different quantitative indicators used by scholars in the study of economic policy uncertainty, its points out that the EPU index of Baker et al. (2016) is the most popular and scientific way to quantify. This paper formally carries out characteristic analysis based on EPU index. In the process of analyzing China's EPU index, this paper first makes a simple analysis of the EPU index of the world's major economies, in order to make a comparison with China's EPU index. Secondly, we use GARCH model to make an empirical analysis of EPU index. Through calculation, we find that China's EPU index has three characteristics: volatility clustering, autocorrelation and heteroscedasticity. Although all kinds of events or economic development have led to policy changes, policy changes themselves will have a series of consequences. Appropriate adjustment of economic policies is conducive to better adapting to economic development and promoting the healthy operation of the national economy. However, it can't be ignored that too frequent policy adjustment will lead to investors and the public to have insecurity, thus hindering the normal operation of the economy. Therefore, managers must strive for a reasonable adjustment of policies according to the current economic development situation, rather than frequent changes.

\section{References}

Baker, S. R., Bloom, N., \& Davis, S. J. (2016). Measuring economic policy uncertainty. The Quarterly Journal of Economics, 131(4), 1593-1636.

Chau, F., \& Wang, J. (2014). Political uncertainty and stock market volatility in the Middle East and North African (MENA) countries. Journal of International Financial Markets Institutions \& Money, 28(1), 1-19.

Guo, H., Wang, C., \& Li, H. (2016). Policy uncertainty, bank credit and enterprise R\&D investment. Macroeconomics, $2016(2), 89-105$.

Hong, H., \& Kostovetsky, L. (2010). Red and blue investing: Values and finance. Journal of Financial Economics, 103(1), 119.

Huang, T., Wu, F., \& Yu, J. (2015). Political risk and dividend policy: Evidence from international political crises. Journal of International Business Studies, 46(5), 574-595.

Scott, R. B., \& Bloom, N. (2013). Does uncertainty reduce growth? Using disasters as natural experiments (No. w 19475): National Bureau of Economic Research.

Xu, Y., Qian, X., \& Li, W. (2013). Political uncertainty, political linkages and investment in private enterprises: Evidence from the replacement of the secretary of the municipal party committee. Management World, 2013(5), 116-130. 